\title{
The Construction of Social Practice Appraisal Mechanism for Graduate Students
}

\author{
Guiyu Dai ${ }^{1}$, Feng Zhou ${ }^{1}$, Xinya Zhang ${ }^{1} \&$ Shumin $\mathrm{Li}^{1}$ \\ ${ }^{1}$ School of English for International Business, Guangdong University of Foreign Studies, China \\ Correspondence: Feng Zhou, School of English for International Business, Guangdong University of Foreign \\ Studies, China
}

Received: July 6, $2021 \quad$ Accepted: August 10, $2021 \quad$ Online Published: August 20, 2021

doi:10.5539/hes.v11n3p134

URL: https://doi.org/10.5539/hes.v11n3p134

\begin{abstract}
As a chief pillar of higher education and technological innovation, universities have been enhancing national innovative capacity and promoting the social and economic development of the nation. Graduate education is an important channel of nurturing high-level talents, of which the cultivation of graduate students' practical ability is at the core. However, there are still some problems existing in the social practice appraisal mechanism for graduate students in most Chinese universities, such as the limited assessment scope, overgeneralized standards, inefficient communication during the social practice process and imperfect incentive mechanism. These deficiencies have made negative impacts on the effectiveness of the assessment of graduate students' practical ability, the quality of graduate students' practice, and the enthusiasm of graduate students involving in social practice. In order to promote the present social practice appraisal mechanism for graduate students, this paper attempts to construct a new graduate student appraisal system through the use of OKR (Objectives and Key Results) management approach and a more comprehensive incentive mechanism, in the hope of contributing to the improvement of the whole graduate student social practice evaluation mechanism.
\end{abstract}

Keywords: graduate students, social practice appraisal mechanism, incentive mechanism, OKR management approach

\section{Introduction}

China has presented remarkable achievements in building socialism with Chinese characteristics, which embarks on a new journey to build a great modern socialist country. The development of CPC and the nation urgently needs a large number of talents with excellent abilities in scientific researches and technological innovation. As the highest-level talented people cultivated by national education, graduate students represent the quality of a country's higher education and scientific development potential, who are the major forces in constructing a great modern socialist country with Chinese characteristics. In the "13th Five-Year Plan" for Degree and Graduate Education Development, the Ministry of Education emphasizes that graduate education is the main channel to cultivate high-level talents and create their values in boosting economic advancement, and an important pillar of the national talent competition and scientific and technological competition, serving as a core element of implementing innovation-driven development strategy and building an innovation-driven country. As early as 2013, the Ministry of Education has stated in the Opinions on Deepening the Reform of Postgraduate Education (Teaching and Research, No. 1 [2013]) that universities and research institutes ought to establish a graduate education system that is oriented by vocational demands, focusing on the cultivation of practical ability of the graduate students and combining production and education as a way to meet the needs of economic and social development. In order to adapt to the rapid national demand for scientific researchers, many colleges and universities have brought the social practice into the graduate training program and listed the social practice course as a compulsory course so as to nurture the social practice ability and scientific research ability of the graduate students and thus improve their comprehensive quality.

The social practice course is an effective link for colleges and universities to promote the development of graduate students in all aspects and to implement the combination between theory and practice of professional knowledge. It also provides a platform to help them step down from the ivory tower and better adapt to their future career. The results of social practice function as the reference for universities to self-check and further improve their graduate training programs. However, how to construct the scientific, effective, and simple social 
practice appraisal mechanism and incentive mechanism, is still a difficult problem to be solved urgently in the management of universities. Relevant scholars point out that the evaluation mechanism of graduate social practice is formalized and lacks specific standards and evaluation indicators, which hinders the corresponding incentive mechanism from giving full play to its role in motivating graduate students to participate in social practice and scientific research practice (Wang \& Zhang, 2012; Shen, 2017).

With the continuous deepening reform of graduate education, many scholars attempt to establish a new appraisal mechanism suitable for each university or even each major based on the existing evaluation mechanism of universities, from the perspectives of education evaluation theory (Zhang, 2004; Jia \& Yao, 2019), the graduate student assistants system in the United States ( $\mathrm{Li} \& \mathrm{Xu}, 2015$; Huo \& $\mathrm{Li}, 2016 ; \mathrm{Li}, 2019$ ), performance management (Wang \& Zhang, 2012) and other perspectives. However, it is found that there are still deficiencies in these mechanisms: 1) the assessment system lacks transparent and quantifiable evaluation indicators; 2) only graduate students are assessed with participants or supervisors of practice not involved in the assessment accordingly; 3) the focus of the assessment lies on the results, failing to pay attention to the growth process of the graduate students in social practice and failing to provide a quantitative performance; 4) there is a lack of an assessment system and incentive mechanism suitable for graduate students majored in Humanities and Social Sciences.

Therefore, taking the social practice mechanism of the School of English for International Business in Guangdong University of Foreign Studies as an example, this paper attempts to build a graduate social practice appraisal mechanism based on OKR management strategies that can quantify the practice process and practice results, as well as the corresponding incentive mechanism. It aims to make up for the shortcomings of the previous evaluation mechanism, correctly guide and effectively encourage the graduate students to participate in research training and social practice, so as to better cultivate the graduate students' scientific research ability and practical ability to adapt to the social development.

\section{The Existing Problems of Social Practice Appraisal Mechanism}

The social practice assessment of postgraduate students is an important part of the graduate training program. Most colleges and universities have corresponding social practice appraisal mechanisms. However, currently, the social practice evaluation in many colleges and universities is a mere formality, the evaluation mechanism is not mature, and the whole evaluation system still needs to be further improved. Taking the School of English for International Business (SEIB) of Guangdong University of Foreign Studies as an example, the current social practice evaluation mechanism in the graduate course credit management of the school is simple and easy for teachers and postgraduate students to operate. However, in the process of actual implementation, we found that the current social practice assessment still had the following four problems.

\subsection{The Limitations of Social Practice Assessment Scope}

Currently, the postgraduate social practice course is offered in the first semester of the second year of postgraduate study in the SEIB, which is mainly composed of teaching practice and academic research practice. Specifically, the teaching practice includes 36-hour work of teaching assistant, administrative assistant in the school, and off-campus teaching practice. The academic research practice includes 36 hours of academic research project assistant and personal published academic articles.

In principle, the school encourages postgraduate students to make full use of their spare time to enrich their practice by joining in both social practice and academic research practice. However, in the practical assessment, postgraduate students can choose to complete either of the two sections, which indicates that if postgraduate students can complete academic practice, they do not need to complete the social practice. Nevertheless, both social practice and academic research practice are important forms of graduate professional practice. Contemporary postgraduate students not only need to learn skills related to social practice to improve their working ability but also need to do academic research and master certain scientific research ability in order to make contributions to society.

Many postgraduate students majoring in business English choose to participate in internships at enterprises. At present, the SEIB does not evaluate postgraduate students' internships in enterprises, because the scope of social practice assessment is limited to teaching practice. It is more like the social practice assessment of English major postgraduate students, which deviates slightly from the training goal of business English postgraduate students. From the perspective of talent cultivation, business English major is more inclined to cultivate foreign language application-oriented talents. However, the school has not included enterprise internships into the scope of social practice assessment, remaining certain limitations. 
In addition, the practice resources provided by the SEIB are relatively scarce. At present, the school does not provide school-enterprise cooperation projects or practice bases. School-enterprise cooperation projects can combine the advantages of the basic knowledge of school tutors with the advantages of the practical experience of enterprises, so as to improve the academic and practical ability of postgraduate students. Moreover, in the actual implementation, school-enterprise cooperation projects are more conducive to the supervision and evaluation of the whole social practice process of postgraduate students, which can not only guarantee the quality of social practices but also provide good internship opportunities for postgraduate students.

It can be concluded from the discussion above that taking the social practice course of the SEIB as an example, the current social practice appraisal mechanism for language major postgraduate students in universities is not complete, which lacks communication with enterprises, and fails to provide high-quality social practice opportunities for postgraduate students.

\subsection{The Overgeneralization of Social Practice Assessment Standards}

The formalization of social practice assessment in colleges and universities is the biggest problem of the current social practice appraisal mechanism. The current assessment in the SEIB is that the social practice course teacher marks the practice reports and relevant certification materials submitted by postgraduate students, but the current assessment standards are vague and need to be further improved.

The social practice score criteria of the SEIB are oversimplified, lacking scientific and detailed assessment indicators and scoring standards. There are few specific assessment indicators for teaching practice. Postgraduates are only required to fill the basic information in the report. The assessment criteria are also relatively general. The grading criteria are not clear because there are only four options for performance scoring: excellent, good, pass and fail. In actual operation, there are also some problems in teaching practice assessment. The school has no specific assessment forms and standards for the assessment of teaching assistants and administrative assistants of the school, making it difficult to evaluate postgraduate students' performance.

In addition, after interviewing the course teacher, we found that there is no significant difference between the scores of postgraduates with rich practice experience and those with simple practice experience. The score is completely based on the final report submitted by the postgraduate students, and there is no corresponding assessment on the quality of the practice process. Moreover, the quality of off-campus social practice participated by postgraduate students is uneven, so it is difficult to control the standard of evaluation and quantify the detailed criteria of scoring.

\subsection{The Insufficiency of Effective Communication in Social Practice Process}

Effective communication between school supervisors, students, and organizations is the premise of ensuring the quality of social practice assessment. However, in the process of teaching practice, there lacks of effective communication channels between the school and students. The school fails to collect information related to students' social practices in time, resulting in the failure to supervise students' practice process. Besides, the scores of practice assessment are merely based on students' practice reports, and the school cannot even confirm whether postgraduates participated in practice activities. Moreover, there is no corresponding communication channel between the organizations and the administrative department of the school, and the organizations cannot give feedback on student's practical performance, comprehensive ability, and psychological state to the school in time, which are not conducive to the assessment of social practice.

\subsection{The Imperfection of Incentive Mechanism for Social Practice}

The current appraisal mechanism of the SEIB does not play its corresponding incentive role and does not fully motivate postgraduate students. The main motivative method is to add points to the comprehensive test of the academic year scholarship. The additional points in the comprehensive test are mainly focused on academic practice. Postgraduates can publish academic papers through academic research practice, and then the academic achievements can be used as a reference of scholarship in accordance with the relevant rules. However, only a small number of postgraduate students participate in academic research practice projects and publish academic papers every year, while teaching practice and enterprise practice are not included in the comprehensive test, which weakens the enthusiasm of postgraduates to participate in social practice to a certain extent.

In terms of material awards, the school mainly provides financial support for academic practice, such as reimbursement for postgraduate students to attend academic conferences and part of tuition fees for students to study abroad. In addition, the incentive methods of teaching practice and enterprise practice are mainly monthly subsidies provided by the school and companies. Although there is a fixed monthly subsidy for teaching and administrative assistant for school, the salary is not high, and a lack of incentive measures, which leads to 
students' low enthusiasm for work. From the perspective of spiritual awards, the school does not pay attention to the relevant honors students have won in social practice, which makes students lack the motivation to participate in social practice. All these show that the current incentive mechanism of the school is still immature and does not combine material and spiritual awards properly.

\section{The Construction of New Social Practice Appraisal Mechanism}

In order to address the mentioned problems of limited assessment scope, overgeneralization assessment standards, and lack of effective communication in social practice, this paper attempts to improve the existing appraisal mechanism by admitting off-campus social practice projects and proposing new systematic assessing procedures.

As shown in table 1, the new assessment scope is extended into three major parts (teaching practice, company internship, and volunteer activities) in which the latter two parts are newly added and the academic practice will no longer be evaluated as one of the social practice items.

Table 1. The Assessment Scope of Social Practice

\begin{tabular}{|c|c|}
\hline \multirow{4}{*}{$\begin{array}{l}\text { Social Practice Projects } \\
\text { Teaching Practice }\end{array}$} & Specific Tasks \\
\hline & Teaching assistant \\
\hline & Administrative assistant for the school \\
\hline & Student teacher at other organizations \\
\hline Company Internship & $\begin{array}{l}\text { Intern at school-enterprise cooperative project } \\
\text { Intern at other companies }\end{array}$ \\
\hline Volunteer Activities & $\begin{array}{l}\text { Volunteers in university activities } \\
\text { Volunteers in national or provincial activities }\end{array}$ \\
\hline
\end{tabular}

Compared with the previous assessment content, the creative advantages of the assessment scope of new social practice are presented in two aspects. First, adding enterprise practice into the existing assessment items can help postgraduates who plan to work in enterprises after graduation to effectively combine acquired knowledge with professional practice to gain working experiences for their future career. Second, volunteer activities can encourage postgraduate students not only to participate in academic and practical studies but to proactively act upon their professional intelligence in social activities. Moreover, it would also evoke and nurture a strong sense of social responsibility of postgraduates.

In general, the assessment scope of the new appraisal mechanism covers a wider range of social practice, aiming to comprehensively evaluate postgraduates' abilities in social practice and to make up for the deficiency of the previous appraisal mechanism that only focuses on teaching practice. Therefore, this paper will establish a systematic managing platform for postgraduates' social practice appraisal mechanism.

\subsection{Setting up a System for Releasing Information and Reporting Practice Progress}

The previous on-campus practice only contains teaching assistant and administrative assistant. Graduate students submit written applications as the school releases social practice information, and then the school will allocate the positions. However, the application for previous social practice lacks positions of company internship and volunteer activities, relying more on paper materials thus consuming more time and manpower. In this respect, this paper intends to make full use of Internet technology to establish a tracking platform supervising all the procedures in postgraduates' social practice.

The platform allows postgraduate students and their supervisors in schools or enterprises to view the relevant information and to make adjustments accordingly. First of all, the school releases social practice positions description and specific requirements in the system. Secondly, postgraduates $\log$ in to the system to select posts according to their personal needs, applying for them, and submit the required materials. Then, the school or enterprise will review the applications and give feedback on whether approve or not to appliers. Finally, the graduate can sign the agreement with the school or enterprises and start social practice.

Other than the posts provided by the school, the corresponding reporting function is designed for the postgraduate students to participate in the social practice outside of the school. Students are supposed to submit their practice information in the system with the approval of supervisors at school. Before starting their internship, the school will check whether the company is qualified and whether it is within the scope of social practice assessment. 


\subsection{Tracking Social Practice Process through OKR Management Approach}

Process monitoring and result identification serve as the two effective procedures in assessing postgraduates' social practice performance. At present, the results of social practice are evaluated based on a practice report and its related materials submitted at the end of practice, which pertains to summative assessment and slightly neglects the periodical performance of postgraduates in their practice process. For this reason, the OKR management approach is applied to optimize previous social practice appraisal mechanism, measure progresses made by postgraduates, and pay more attention to the efforts they have made in the whole process of social practice.

OKR, abbreviated form of Objective and Key Results, is a goal management framework that helps to establish measurable goals and track outcomes over a period of time. According to John Doerr (2018) who introduces OKR to Google, "objectives define what we seek to achieve; key results are how those top-priority goals will be attained with specific, measurable actions within a set time frame". In this goal-setting system, it is recommended to set up 3 to 5 OKRs during a short period of time and objectives should be short but quantifiable (Niven \& Lamorte, 2016). When OKR is applied to this case, it is expected to refine the general criteria for postgraduates' social practice performance assessment and emphasize more on the periodical growth of postgraduates. The superiority of the OKR approach is presented in its transparency and convenience for adjusting key metrics in real-time, allowing the school, supervisors, and postgraduates to communicate with each other about the problems existing in the objectives, key results, and progress records in time. Through the application of OKR, the school can supervise the social practice process of postgraduates to ensure that they have fully engaged in their own social practice. At the same time, this record in the system can also be taken into the practice assessment file as a key indicator for the final social practice assessment.

Therefore, postgraduates are supposed to proactively record and upload their OKRs and other detailed information to the system according to their own practice progress. The specific contents include: 1) setting objectives according to their own work contents; 2) identifying the desired and measurable outcomes that match the objectives; 3 ) recording the progress and submitting the weekly report in the system.

\subsection{Refining Grading Criteria for Social Practice}

The appraisal content of postgraduates' social practice covers personal social practice information, tracking records of OKRs and final reports, of which tracking records of OKRs will be evaluated by social practice supervisors from the validity of OKRs setting and the fulfillment of objectives, and the final report will be graded by the school from 8 criteria (general performance, attendance, practice attitude, personal ability, work efficiency, practical contributions to work team, personal growth, practice reflection). In this paper, the Delphi method, also known as the expert evaluation method, is used to refine the weight of evaluation indicators. After consultation with experts and repeated modification, the evaluation weight is concluded as OKRs Tracking Records: Social Practice Report $=60: 40$ (full grade of 100).

This section takes teaching practice as an example to explain the application of the refined grading criteria. Referring to OKRs setting formula suggested in the book Measure what Matters (Doerr \& Page, 2018) "I will as measured by __. .", the objectives of teaching practice as primary and secondary school teachers are set from different perspectives, including basic teaching work, teaching results, curriculum construction, and students' achievement. Accordingly, key results are set to measure progress towards each objective. The score of OKRs tracking records should be averaged out based on the number of objectives. As a $70 \%$ fulfillment of key results is considered a success, postgraduates who have set up feasible objectives will gain 20 points, one-third of the full mark of OKRs tracking records. In addition to basic points, the other forty are graded by the completion of practical key results. The specific OKRs Settings of teaching practice are shown in Table 2: 
Table 2. OKRs Settings of trainee teachers in primary and secondary schools

\begin{tabular}{|c|c|c|}
\hline Objective & Key Results & Score \\
\hline $\begin{array}{l}\text { Basic teaching } \\
\text { work }\end{array}$ & $\begin{array}{l}\text { Complete the basic } \\
\text { teaching work according } \\
\text { to the teaching plan }\end{array}$ & $\begin{array}{l}3 \text { for accomplishing less than } 50 \% \text { of basic teaching work } \\
5 \text { for accomplishing } 50-80 \% \text { of basic teaching work } \\
8 \text { for accomplishing } 80 \%-100 \% \text { of basic teaching work } \\
10 \text { for overdoing basic teaching work }\end{array}$ \\
\hline $\begin{array}{l}\text { The teaching } \\
\text { results }\end{array}$ & $\begin{array}{l}\text { The improvement } \\
\text { of the class grade }\end{array}$ & $\begin{array}{l}3 \text { for no fluctuation in the average grade of the class } \\
5 \text { for an increase of } 10 \% \text { in the average grade of the class } \\
8 \text { for an increase of } 20 \% \text { in the average grade of the class } \\
10 \text { for an increase of more than } 30 \% \text { in the average } \\
\text { grade of the class }\end{array}$ \\
\hline Curriculum construction & $\begin{array}{l}\text { 1. Completion of open } \\
\text { courses each semester } \\
\text { 2. Awards for } \\
\text { teaching achievements } \\
\text { 3. Numbers of } \\
\text { high-quality courses }\end{array}$ & $\begin{array}{l}4 \text { for completing the required open courses } \\
8 \text { for gaining remarkable teaching achievements } \\
10 \text { for awarding excellent courses }\end{array}$ \\
\hline Students' achievement & $\begin{array}{l}\text { 1. Entry-level of } \\
\text { competition } \\
\text { 2. Rankings in the } \\
\text { competition }\end{array}$ & $\begin{array}{l}3 \text { for winning in the school competition } \\
5 \text { for winning in the municipal competition } \\
8 \text { for winning the provincial competition } \\
10 \text { for winning the national competition }\end{array}$ \\
\hline
\end{tabular}

In addition to the OKRs assessment on teaching practice, the results of the practice, personal growth during the practice, and reflection also need to be appraised. Therefore, postgraduate students are required to submit a practice report at the end of social practice, which mainly includes practice contents, OKRs settings in each stage, practice results, and practice reflection. Upon submission of practice reports, the teacher will grade the report according to the following eight assessment items, including general performance, attendance, personal ability, attitudes toward the practice, work efficiency, practical contributions, growth during practice, and personal reflection on social practice. Each item is constituted of 5 points of the total 40, and the teacher will grade the report referring to the content in the practice report and the feedback from supervisors in social practice. The report assessing scale is shown in Table 3:

Table 3. Practice Report Assessing Scale

\begin{tabular}{|c|c|c|c|c|c|}
\hline \multirow[t]{2}{*}{ Assessment Criteria for social practice } & \multicolumn{5}{|c|}{ Scores } \\
\hline & $1^{\prime}$ & $2^{\prime}$ & $3^{\prime}$ & $4^{\prime}$ & $5{ }^{\prime}$ \\
\hline \multicolumn{6}{|l|}{ General performance } \\
\hline \multicolumn{6}{|l|}{ Attendance } \\
\hline \multirow{2}{*}{\multicolumn{6}{|c|}{$\begin{array}{l}\text { Practice attitude } \\
\text { personal ability }\end{array}$}} \\
\hline & & & & & \\
\hline \multicolumn{6}{|l|}{ Work efficiency } \\
\hline \multicolumn{6}{|l|}{ Practical contributions to work team } \\
\hline \multicolumn{6}{|l|}{ Personal growth } \\
\hline Practice reflection & & & & & \\
\hline
\end{tabular}

It can be concluded that the formulas for calculating the total score of the social practice of postgraduate students are as follows (St: total score; Sb: OKRs base score; Ki: OKRs sub-item score; Ri: Score of each item in the practice assessing scale):

$$
\mathrm{St}=\sum(\mathrm{Sb}+\mathrm{K} 1+\mathrm{K} 2+\mathrm{K} 3+\mathrm{K} 4)+(\mathrm{R} 1+\mathrm{R} 2+\mathrm{R} 3+\mathrm{R} 4+\mathrm{R} 5+\mathrm{R} 6+\mathrm{R} 7+\mathrm{R} 8)
$$

Total score $=60$ points of OKRs tracking records (basic score $20+$ cumulative score 40 ) + practice report 40 points

The following examples illustrate the specific operation of the new assessment and scoring criteria. Assuming that postgraduate $\mathrm{X}$ has conducted teaching practice in a middle school, the score of OKRs tracking records of a semester and the score of the practice report scale are shown in Table 4 and Table 5 respectively. 
Table 4. OKRs Tracking Records Score of Postgraduate X's Teaching Practice

\begin{tabular}{|c|c|c|c|c|}
\hline Object & Key results & The Completion of KRs & $\begin{array}{l}\text { The KRs } \\
\text { score }\end{array}$ & $\begin{array}{l}\text { OKRs } \\
\text { total score }\end{array}$ \\
\hline $\begin{array}{l}\text { Basic teaching } \\
\text { work }\end{array}$ & $\begin{array}{l}\text { Complete the basic teaching work } \\
\text { according to the teaching plan }\end{array}$ & $\begin{array}{l}80-100 \% \text { completion } \\
\text { of the work }\end{array}$ & 8 & 46 \\
\hline $\begin{array}{l}\text { The teaching } \\
\text { results }\end{array}$ & $\begin{array}{l}\text { The improvement of the } \\
\text { class grade }\end{array}$ & $\begin{array}{l}\text { The average grade of } \\
\text { the class increased by } 10 \%\end{array}$ & 5 & \\
\hline $\begin{array}{l}\text { Curriculum } \\
\text { construction }\end{array}$ & $\begin{array}{l}\text { 1. Completion of open } \\
\text { courses each semester } \\
\text { 2. Awards for teaching achievements } \\
\text { 3. Numbers of high-quality courses }\end{array}$ & $\begin{array}{l}\text { completing the required } \\
\text { open courses } \\
\text { gaining remarkable } \\
\text { teaching achievements }\end{array}$ & 8 & \\
\hline $\begin{array}{l}\text { Students' } \\
\text { achievement }\end{array}$ & $\begin{array}{l}\text { 1. Entry-level of competition } \\
\text { 2. Rankings in the competition }\end{array}$ & $\begin{array}{l}\text { Students won awards } \\
\text { in the municipal competition }\end{array}$ & 5 & \\
\hline
\end{tabular}

Table 5. Practice Report Assessing Scale of Postgraduate X

\begin{tabular}{llllll}
\hline Assessment Criteria for social practice & \multicolumn{5}{l}{ Scores } \\
& $1^{\prime}$ & $2^{\prime}$ & $3^{\prime}$ & $4^{\prime}$ & $5^{\prime}$ \\
\hline General performance & & & $\sqrt{ }$ & \\
Attendance & & & & $\sqrt{ }$ \\
Practice attitude & & & & $\sqrt{ }$ \\
personal ability & & $\sqrt{ }$ & \\
Work efficiency & & $\sqrt{ }$ & \\
Practical contributions to work team & & $\sqrt{ }$ & & \\
Personal growth & & & $\sqrt{ }$ & \\
Practice reflection & & & & $\sqrt{ }$ \\
Total & & & & & \\
\hline
\end{tabular}

The final social practice score of the postgraduate is $80(46+34)$.

\subsection{Operating Procedures of Social Practice Appraisal mechanism for Graduate Students}

Based on the above discussion, this study takes the School of International Business English of Guangdong University of Foreign Studies as an example, aiming to establish a social practice appraisal mechanism for postgraduates majoring in humanities and social sciences. The mechanism mainly contains a platform for releasing social practice information and submitting practice report, an OKR management approach of tracking periodical growth of postgraduates, and quantitative social practice assessing strategies. The complete operating procedures of the social practice appraisal mechanism is shown in Figure 1: 


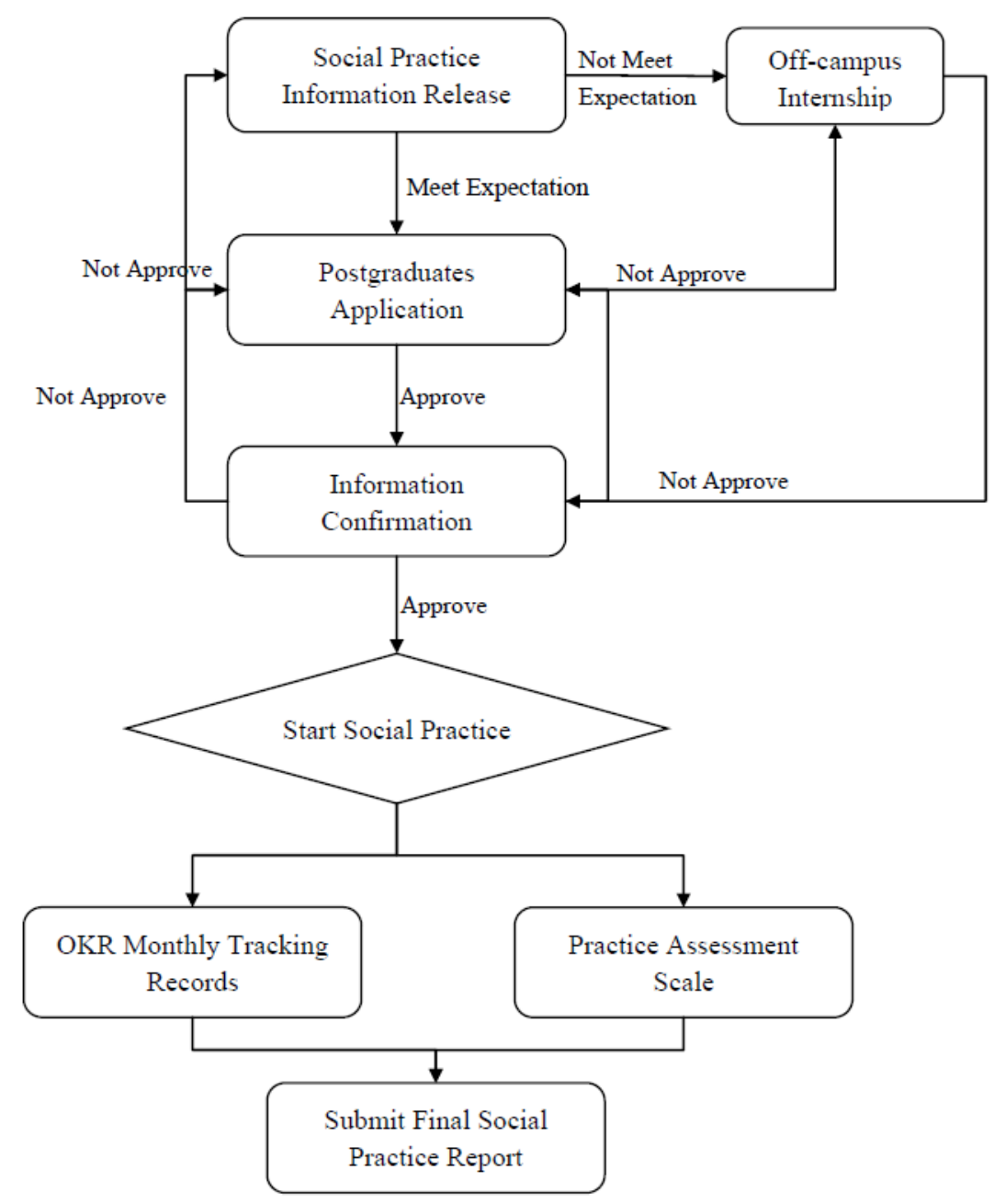

Figure 1. Operation Flow Chart of Social Practice Evaluation Mechanism of Graduate Students

As shown in figure 3-1, first of all, the school or the enterprise posts the social practice information through the school platform where postgraduates can choose a certain social practice according to their personal interests and need. If the post settings meet their expectations, postgraduate students can further apply for and report to confirm the post, but if the officially released information fails to meet their expected needs, postgraduates can participate in off-campus social practice by themselves. The prerequisite lies in actively reporting it to the platform and waiting for the university to confirm the qualification of companies. Secondly, only after the school, the supervisor, and the postgraduate students have confirmed the practice information, can they officially engage in their social practice. Finally, students are supposed to set their OKR (Objectives and Key Results) based on personal needs and the requirements of different practice positions under the guidance of teaching supervisors or enterprise mentors. Besides, they should submit it to the platform to track the practice process at the beginning of the project cycle and adjust OKRs settings regularly in accordance with feedbacks. In the practice process, postgraduates should combine theory with practice by putting professional knowledge into use and conscientiously accomplishing social practice work. During the social practice, their performance is assessed monthly by supervisors of teaching practice or mentors of company internships. At the end of social practice, students need to submit a complete social practice report (including OKRs monthly tracking records, practice assessment scale, and practice reflection report) which will be evaluated and scored by the teachers in charge of social practice.

\section{The Construction of Incentive Mechanism for Social Practice}

At present, the incentive mechanism of social practice in colleges and universities in China is not complete enough, and there are still some problems, such as rigid incentive methods, and insufficient rewards. Therefore, 
in order to match with the reform of social practice evaluation mechanism, it is necessary to build a more complete award mechanism, which should be improved mainly from the following aspects:

Firstly, extend the incentive scope of social practice. At present, postgraduate students' social practice incentive is mainly focused on academic research practice but does not involve teaching practice and enterprise practice, so it is difficult to motivate students to participate in those practices. It shows that the current incentive scope is not broad enough to fully cover social practice activities. Therefore, in order to construct a more comprehensive incentive mechanism for social practice, teaching practice and enterprise practice need to be included in the incentive scope. The school can award outstanding students according to the assessment results of social practice, so as to encourage students to participate more in social practice.

Secondly, enrich the forms of incentives for social practice. At present, the forms of students' social practice awards mainly contain material rewards and add points in the comprehensive test. In summary, the current incentive method is relatively simple. Therefore, colleges and universities should reform the current incentive mechanism, enrich the forms of awards, and combine material rewards with spiritual rewards to motivate students. In addition, colleges and universities should add social practice projects into the scope of additional scores, refine detailed rules for additional scores, and ensure fairness and openness. Moreover, postgraduates who perform well in social practice assessment can also be given spiritual awards and certificates of honor. This kind of spiritual encouragement can also be linked with scholarship evaluation, which has a certain impact on the comprehensive test.

Thirdly, improve the incentive mechanism support system. Incentive methods cannot be separated from the support of manpower, material, and finances. Therefore, the local government should appropriately increase the financial support for social practice projects in colleges and universities to ensure the funds needed for the incentive mechanism of social practice. Colleges and universities should also strengthen communication and cooperation with local governments and all sectors of society, establish long-term school-enterprise cooperation projects and practice bases, and provide substantial supports for the social practice of postgraduate students. According to the budget allocated by the government, colleges and universities should make reasonable arrangements on the expenses of practical training courses and reimburse the actual operating costs. Also, excellent joint graduate training bases can be selected according to the enterprise's practical training and students' practical performance, so as to encourage enterprises to participate in the social practice teaching of postgraduate students.

Fourthly, social practice assessment should be included in the evaluation of the quality of colleges and universities. From the macro perspective, colleges and universities should include social practice in the postgraduate training plan. The Ministry of Education can take the performance of social practice assessment of colleges and universities as an important indicator to evaluate the quality of school operation, so as to encourage the administrative departments of colleges and universities to pay more attention to the social practice of postgraduate students. At the same time, universities with outstanding performance should be praised and publicized, and other universities would be encouraged to follow. From the perspective of schools, universities should set up corresponding social practice assessment courses, and assign appropriate social practice tutors for each postgraduate student. The excellent performance of students can also serve as an important basis for teachers' evaluation of excellence.

Relying on the cooperation between the government, enterprises, and universities, this paper constructs a relatively complete social practice incentive mechanism, which is helpful to improve the quality of the social practice of postgraduate students. At the same time, the incentive mechanism can be constantly adjusted and improved in the actual operation to adapt to different regions and universities and to expand its application scope.

\section{Conclusion}

This paper takes the School of English for International Business in Guangdong University of Foreign Studies as an example to explore the social practice appraisal mechanism for graduate students. It is found through the analysis that problems in the social practice assessment mechanism of this school are: 1) the assessment scope of social practice is limited to teaching practice; 2) the grading criteria lacks detailed evaluative indicators; 3) effective communication between supervisors and graduate students is neglected in the process of social practice; 4) and the incentive mechanism is imperfect.

In order to solve the above problems, this paper improves the existing mechanism by putting forward the new appraisal mechanism and incentive mechanism serving for graduate students majoring in Humanities and Social Science. It is of great significance to construct a new social practice evaluation mechanism, which improves the 
quality of practice and the effectiveness of assessment, and stimulates the enthusiasm of graduate students to proactively engage in social practices. Specific improvements include the establishment of a social practice release platform and reporting system, the use of OKRs to track and monitor the practice process, the refinement of scoring standards, and the quantification of scoring indicators.

The purpose of cultivating graduate students is to provide excellent talents to society. The effective social practice appraisal mechanism is conducive to objectively evaluating the learning and working ability of graduate students, so as to further raise the training standards of graduate students in universities. At the same time, as a performance appraisal strategy, the OKR management approach can stimulate the enthusiasm of graduate students to carry out the social practice, release their creativity, and evoke a sense of achievement and gratification. The social practice reporting system and OKRs tracking records are recommended to all universities when assessing the social practice performance of graduate students. However, this paper only takes teaching practice as an example to illustrate the setting of indicators. In view of the different forms and different types of social practice in different majors, the specific quantitative scoring indicators need to be set according to different practices. Therefore, this mechanism still needs to be improved and applied in a wider range.

\section{References}

Doerr, J., \& Page, L. (2018). Measure What Matters: How Google, Bono, and the Gates Foundation Rock the World with OKRs. New York: Portfolio.

Huo, L., \& Li, L. (2016). From "Assistantship" to "Cultivation" - on Institutional Innovation of Postgraduate Service Assistantship. Journal of Graduate Education, 06, 27-30+66.

Jia, J., \& Yao, X. (2019). Evaluation System Design of Innovation and Entrepreneurship Education in Colleges and Universities-From the Perspective of Consumer-oriented Evaluation Theory. Journal of Northeastern University (Social Science), 82-88+95.

Li, J., \& Xu, S. (2015). Graduate Teaching Assistant System: Practice in American Universities. Academic Degrees \& Graduate Education, 07, 72-77.

Li, X. (2019). TA Education of "the Future College Teachers": Analysis of "Three Stages" of Graduate's Teaching Assistant Training Model in American Colleges and Universities. Journal of Northeast Normal University (Philosophy and Social Sciences), 05, 145-151.

Ministry of Education (MOE), National Development and Reform Commission, Ministry of Finance, China, (2013). Opinions on Deepening the Reform of Postgraduate Education. https://www.moe.gov.Cn/srcsite/A22/s7065/201304/t20130419_1541-18.html

Ministry of Education (MOE), China. (2013). Academic Degrees and Postgraduate Education Development 13th Five-Year Plan [EB/OL]. https://www.gov.Cn/xinwen/2017-01/20/content_5161660.html

Niven, P., \& Lamorte, B. (2016). Driving focus, alignment, and engagement with OKRs. Hoboken: John Wiley \& Sons, Inc. https://doi.org/10.1002/9781119255543

Shen, S. (2017). Study of the Construction of Comprehensive Quality Evaluation System for Graduate Students. Journal of Technical Economics \& Management, 10, 35-39.

Wang, M., \& Zhang, J. (2012). An analysis of the graduate students' examination and evaluation system for the cultivation of innovative talents. Journal of National Academy of Education Administration, 07, 64-68.

Zhang, Q. (2004). Application of CIPP Model in Research-oriented Curriculum Evaluation. Education Research Monthly, 07, 5-7+29.

\section{Copyrights}

Copyright for this article is retained by the author(s), with first publication rights granted to the journal.

This is an open-access article distributed under the terms and conditions of the Creative Commons Attribution license (http://creativecommons.org/licenses/by/4.0/). 